\title{
Effect of anion type in the performance of ionic liquid/poly(vinylidene
}

\section{fluoride) electromechanical actuators}

R. Mejri ${ }^{1,2,3}$, J. C. Dias ${ }^{2,3}$, S. Besbes Hentati ${ }^{1}$, M. S. Martins ${ }^{4}$, C. M. Costa ${ }^{2,3, *}$ S. Lanceros-Mendez ${ }^{2,5,6}$

${ }^{1}$ Laboratoire de Chimie des Matériaux, Faculté des Sciences de Bizerte, Université de Carthage, 7021 Zarzouna, Bizerte, Tunisia.

${ }^{2}$ Departamento/Centro de Física, Universidade do Minho, Campus de Gualtar, 4710-057 Braga, Portugal.

${ }^{3}$ Departamento/Centro de Química, Universidade do Minho, Campus de Gualtar, 4710057 Braga, Portugal.

${ }^{4}$ MEMS-UMinho, Universidade do Minho, Campus de Azurém, 4800-058 Guimarães, Portugal

${ }^{5}$ BCMaterials, Parque Científico y Tecnológico de Bizkaia, 48160-Derio, Spain

${ }^{6}$ IKERBASQUE, Basque Foundation for Science, Bilbao, Spain

\section{Abstract:}

Low voltage actuators based on poly(vinylidene fluoride) (PVDF) with 10, 25 and $40 \%$ 1-hexyl-3-methylimidazolium chloride $\left(\left[\mathrm{C}_{6} \mathrm{mim}\right][\mathrm{Cl}]\right)$ and 1-hexyl-3-methylimidazolium bis(trifluoromethylsulfonyl)imide $\left(\left[\mathrm{C}_{6} \mathrm{mim}\right]\left[\mathrm{NTf}_{2}\right]\right)$ are prepared by solvent casting in order to evaluate the effect of anion size in the bending properties. Independently of the ionic liquid type and content, its presence leads to the crystallization of PVDF in the $\beta$ phase. The addition of ionic liquid into the polymer matrix decreases significantly its degree of crystallinity and the elastic modulus. It is also confirmed the good miscibility between PVDF and IL, determined by the interaction of the $\mathrm{CF}_{2}$ groups from the PVDF chains with the imidazolium ring in the ionic liquid (IL). The AC conductivity of the composites depends both on the amount of ionic liquid content and anion size.

The bending movement of the IL/PVDF composites is correlated to their degree of crystallinity, mechanical properties and ionic conductivity value and the best value of bending response $(0.53 \%)$ being found for IL/PVDF composite with $40 \mathrm{wt} \%$ of $\left[\mathrm{C}_{6} \mathrm{mim}\right][\mathrm{Cl}]$ at an applied voltage of 10 volts square signal.

Keywords: PVDF; ionic liquid; actuators; bending 


\section{Introduction}

The combination of ionic liquids (ILs) and piezoelectric polymers allows the development of a new class of electroactive smart materials $[1,2]$ with suitable electrical, mechanical and electromechanical properties for applications in the areas of sensors and actuators [3-5], energy generation and storage [6, 7] and biomedicine [8, 9], among others. These composites combine the attractive properties of polymers (lightweight, inexpensive, fracture tolerant, pliable and easily processed) with the properties of the ILs (low melting temperature, negligible vapor pressure, high chemical and thermal stabilities, high ionic conductivity, and a broad electrochemical potential window) [1012].

In this scope, one of the most interesting application areas of those materials is the development of electroactive actuators, as they can be operated at lower-voltages when compared with related systems, such as shape memory alloys (SMA), electroactive ceramics (EAC) [13, 14] and conductive polymers or aerogels [15]. Those actuators can achieve large deformations and do not deteriorate under the application of cycling driving voltages or under atmosphere conditions [16-19]. Further, the properties of the ILs, including near-zero vapor pressure and high thermal stability over a broad temperature range, allow to improve lifetime of electroactive actuators and their high temperature $\left(>100^{\circ} \mathrm{C}\right)$ operation $[20]$.

The high value of the electrical conductivity and the large electrochemical windows of ILs can lead to improved actuation speed and strength by tailoring the number of cations and anions as well as their sizes [21].

The first work reporting on the use of ILs for actuators was related to conducting polymer actuators [16], which are driven by doping and undoping of $\pi$-conjugated polymers by redox reactions. Electroactive actuators based on piezoelectric polymer and IL operate in 
a similar way to electric double layer capacitors and can bring advantages in terms of the simplicity and durability with respect to the previous ones [22].

The most interesting and used polymers for electroactive actuators are Nafion [23], poly(vinylidene fluoride) (PVDF) [24] and its copolymers poly(vinylidene fluoride-cochlorotrifluoroethylene) (PVDF-CTFE) [25] and poly(vinylidene fluoride-cohexafluoropropylene), (PVDF-HFP) [26].

PVDF and its copolymers are known by its piezoelectric properties but for large strain actuator application the most relevant characteristics are their high dielectric constant, polarity and ionic conductivity [27].

Thus, large actuator strains have been observed in poly(vinylidene fluoride-cochlorotrifluoroethylene)/poly(methylmethacrylate) (PVDF-CTFE/PMMA) with 1-ethyl3-methylimidazolium trifluoromethanesulfonate ([ $\left.\left.\mathrm{C}_{2} \mathrm{mim}\right][\mathrm{TfO}]\right)[25]$, PVDF-HFP with 1-ethyl-3-methylimidazolium tetrafluoroborate $\left(\left[\mathrm{C}_{2} \mathrm{mim}\right]\left[\mathrm{BF}_{4}\right]\right)[26]$ and PVDF-HFP with $\left[\mathrm{C}_{2} \mathrm{mim}\right]\left[\mathrm{BF}_{4}\right]$ with two bucky-gel electrode layers, the latter showing a maximum stress and strain of 4.7 $\mathrm{MPa}$ and $1.9 \%$, respectively [5]. Further, PVDF-HFP actuators have been developed also with other IL such as $\left[\mathrm{C}_{2} \mathrm{mim}\right]\left[\mathrm{BF}_{4}\right]$ and 1-ethyl-3methylimidazolium bis(trifluoromethylsulfonyl)imide $\left(\left[\mathrm{C}_{2} \mathrm{mim}\right]\left[\mathrm{NTf}_{2}\right]\right)[28]$. The largest strains (up to 4\%) have been developed with Nafion and ILs such as 1-ethyl-3methylimidazolium hexafluorophosphate $\left(\left[\mathrm{C}_{2} \mathrm{mim}\right]\left[\mathrm{PF}_{6}\right]\right)$ and 1-hexyl-3methylimidazolium hexafluorophosphate $\left(\left[\mathrm{C}_{6} \mathrm{mim}\right]\left[\mathrm{PF}_{6}\right]\right)$, without any signs of back relaxation [22].

Thus, suitable actuators are developed with PVDF based polymers and IL such as IL: 1ethyl-3-methylimidazolium bis(trifluoromethylsulfonyl)imide, $\left[\mathrm{C}_{2} \operatorname{mim}\right]\left[\mathrm{NTf}_{2}\right]$ [29], the electrical transport process being one of the critical issues in actuator performance that must be further investigated. As IL based on 1-n-alkyl-3-methylimidazolium cation 
$\left[\mathrm{Cnmim}{ }^{+}\right]\left[\mathrm{X}^{-}\right]$are among the most interesting for actuator applications, the goal of this work is the preparation of PVDF composites with 1-hexyl-3-methylimidazolium bis(trifluoromethylsulfonyl)imide $\left(\left[\mathrm{C}_{6}\right.\right.$ mim $\left.]\left[\mathrm{NTf}_{2}\right]\right)$ and 1-hexyl-methylimidazolium chloride $\left(\left[\mathrm{C}_{6} \mathrm{mim}\right][\mathrm{Cl}]\right)$ in order to evaluate the effect of anion size $\left([\mathrm{Cl}]^{-}: 25.9 \mathrm{~cm}^{3} \mathrm{~mol}^{-1}\right.$ and $\left.\left[\mathrm{NTf}_{2}\right]^{-}: 158.7 \mathrm{~cm}^{3} \mathrm{~mol}^{-1}[30]\right)$ and filler content on bending actuation. Thus, the objective of the present study it to determine the role of the anion size and IL content on the performance of the actuators. 


\section{Experimental}

\subsection{Materials}

Poly(vinylidene fluoride) (PVDF, Solef 6020) and N,N-dimethylformamide (DMF) were obtained from Solvay and Merck, respectively. The ionic liquids 1-hexyl-3methylimidazolium chloride $\left(\left[\mathrm{C}_{6} \mathrm{mim}\right][\mathrm{Cl}]\right)$ and 1-hexyl-3-methyl imidazolium bis(trifluoromethylsulfonyl)imide $\left(\left[\mathrm{C}_{6} \mathrm{mim}\right]\left[\mathrm{NTf}_{2}\right]\right)$ where acquired in liquid form from Iolitec (Germany) with a purity of $99 \%$.

\subsection{Sample preparation}

For the preparation of the composite films, 1g of PVDF was dissolved at room temperature under magnetic stirring for $\sim 4 \mathrm{~h}$ in $6 \mathrm{~mL}$ of DMF with a polymer/solvent ratio of $15 / 85 \mathrm{w} / \mathrm{v}$. Then, the ionic liquid was added to the solution, the relative ionic liquid/polymer concentration ranging from 10 up to $40 \%(\mathrm{w} / \mathrm{w})$. The IL content within the composite films were chosen taking into account the compatibilization and miscibility between PVDF and ILs, as well as the corresponding electrical properties. After complete homogenization, the solution was spread at room temperature on a clean glass substrate and the solvent was evaporated at $210^{\circ} \mathrm{C}$ for 10 minutes in an air oven (Binder, ED23) and cooling down at room temperature $\left(\sim 23^{\circ} \mathrm{C}\right)$. The thickness of the obtained ILs/PVDF films is $\sim 50 \mu \mathrm{m}$.

\subsection{Characterization of the samples}

The morphology of the samples was evaluated by scanning electron microscopy (SEM) with a Quanta 650 FEG (FEI) scanning microscope. Previously, the samples were coated with gold using a magnetron sputtering Polaron Coater SC502. 
Fourier transformed infrared spectroscopy (FTIR) measurements were performed at room temperature with a JASCO FT/IR-4100 spectrometer in the attenuated total reflection (ATR) mode. FTIR spectra were collected with 64 scans and a resolution of $4 \mathrm{~cm}^{-1}$ in the spectral range between 650 and $4000 \mathrm{~cm}^{-1}$.

Differential scanning calorimetry measurements (DSC) were performed in a DSC 200 F3 Maia NETZSCH apparatus at a heating rate of $10{ }^{\circ} \mathrm{C} \mathrm{min}^{-1}$. The samples were cut into small pieces and placed into $25 \mu \mathrm{L}$ aluminium pans. Experiments were performed from 25 to $200{ }^{\circ} \mathrm{C}$ under nitrogen purge.

Dielectric measurements were carried out using a Quadtech 1929 Precision LCR meter at room temperature in the frequency range from $20 \mathrm{~Hz}$ to $1 \mathrm{MHz}$ with an applied voltage of $0.5 \mathrm{~V}$. The samples were prepared in the form of a parallel plate condenser with circular gold electrodes ( $5 \mathrm{~mm}$ diameter) deposited by magnetron sputtering with a Polaron Coater SC502. The capacity and the dielectric losses were recorded and the real and imaginary parts of the dielectric constant were obtained taking into consideration the geometrical characteristics of the samples. The a.c. conductivity was calculated from [31]:

$$
\sigma^{\prime}(\omega)=\varepsilon_{0} \omega \varepsilon^{\prime \prime}(\omega)
$$

where $\varepsilon_{0}$ is the permittivity of free space, $\omega=2 \pi f$ is the angular frequency and $\varepsilon^{\prime \prime}(\omega)=\varepsilon^{\prime} \tan \delta$ is the frequency dependent imaginary part of the dielectric permittivity

Stress-strain mechanical measurements were carried out in samples with dimensions of $15 \mathrm{~mm} \times 10 \mathrm{~mm}$ with an AG-IS universal testing machine from Shimadzu with a load cell of $50 \mathrm{~N}$. Tests were performed in the tensile mode at room temperature $\left(\sim 23^{\circ} \mathrm{C}\right) \mathrm{using}$ a stretching rate of $1 \mathrm{~mm} \mathrm{~min}^{-1}$. 
Bending measurements were performed using a high definition camera Logitech HD 1080p connected to a PC and a home-made sample holder. The camera allows the analysis of the sample movements with $200 \mu \mathrm{m}$ accuracy. The samples were prepared in the form of $12 \mathrm{~mm} \times 2 \mathrm{~mm}$ rectangles and fixed using two needles, leaving a free length of $10 \mathrm{~mm}$. The sample-holder was then connected to an BK precision 4053 function generator and an oscilloscope PicoScope 4227 was placed in parallel to the sample to detect possible short-circuits and guarantee the electrical integrity of the samples along the tests. Figure 1 shows the schematic representation of the displacement measurement procedure as well as of the internal structure variation of the actuator under applied voltage.

The samples were driven by a square wave signal with three peak voltages: $2.5,5$ and 10 Volts at a frequency of $0.1 \mathrm{~Hz}$, allowing anion and cation migration to the electrodes.

The measurements were evaluated by analysing the movement of the films every 5 seconds. Bending $(\varepsilon)$ was calculated after measuring the sample displacement along the $\mathrm{x}$ axes according to the equation 2 [28]:

$$
\varepsilon=\frac{2 d \delta}{L^{2}+\delta^{2}} \times 100
$$

where $\mathrm{L}$ is the sample free length, $\mathrm{d}$ the thickness $\delta$ the displacement. The measured displacement $\delta$ was transformed into the curvature (1/R) by equation 3[5]:

$$
\frac{1}{R}=\frac{2 \delta}{L^{2}+\delta^{2}}
$$

where $\mathrm{R}$ is the curvature radius and $\mathrm{L}$ is the length of the sample. 


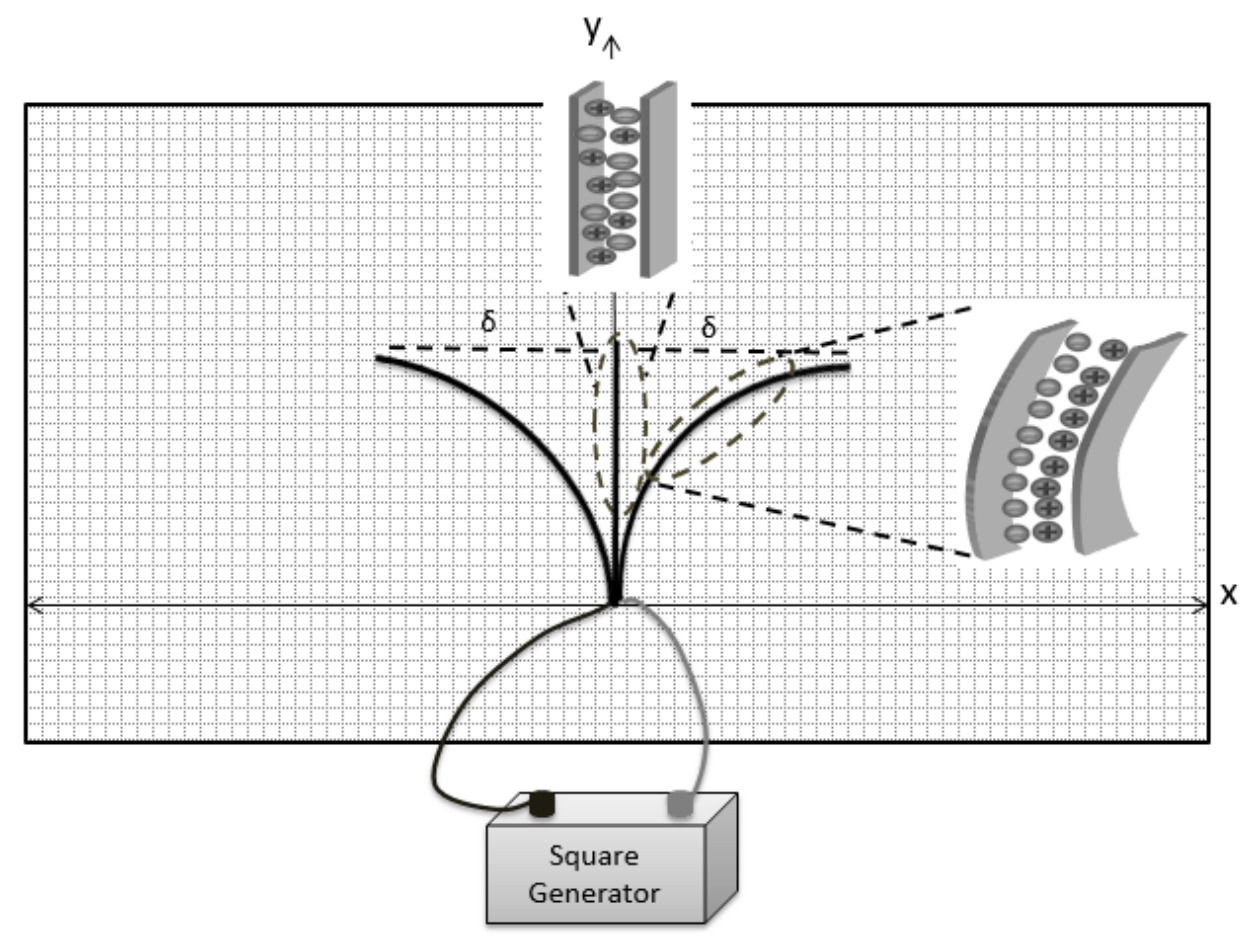

Figure 1 - Schematic representation of the displacement measurement procedure

Sample characterization and actuator performance measurements were performed at least in triplicate and the average value and standard deviation were calculated. 


\section{Results and discussion}

\subsection{Morphology, polymer phase and thermal properties}

\subsubsection{Morphological variations}

Characteristic SEM images of the pristine polymer and the IL/polymer composites are represented in Figure 2 for both IL types, showing that for both IL types, the spherulitic microstructure characteristic of PVDF is observed [32].
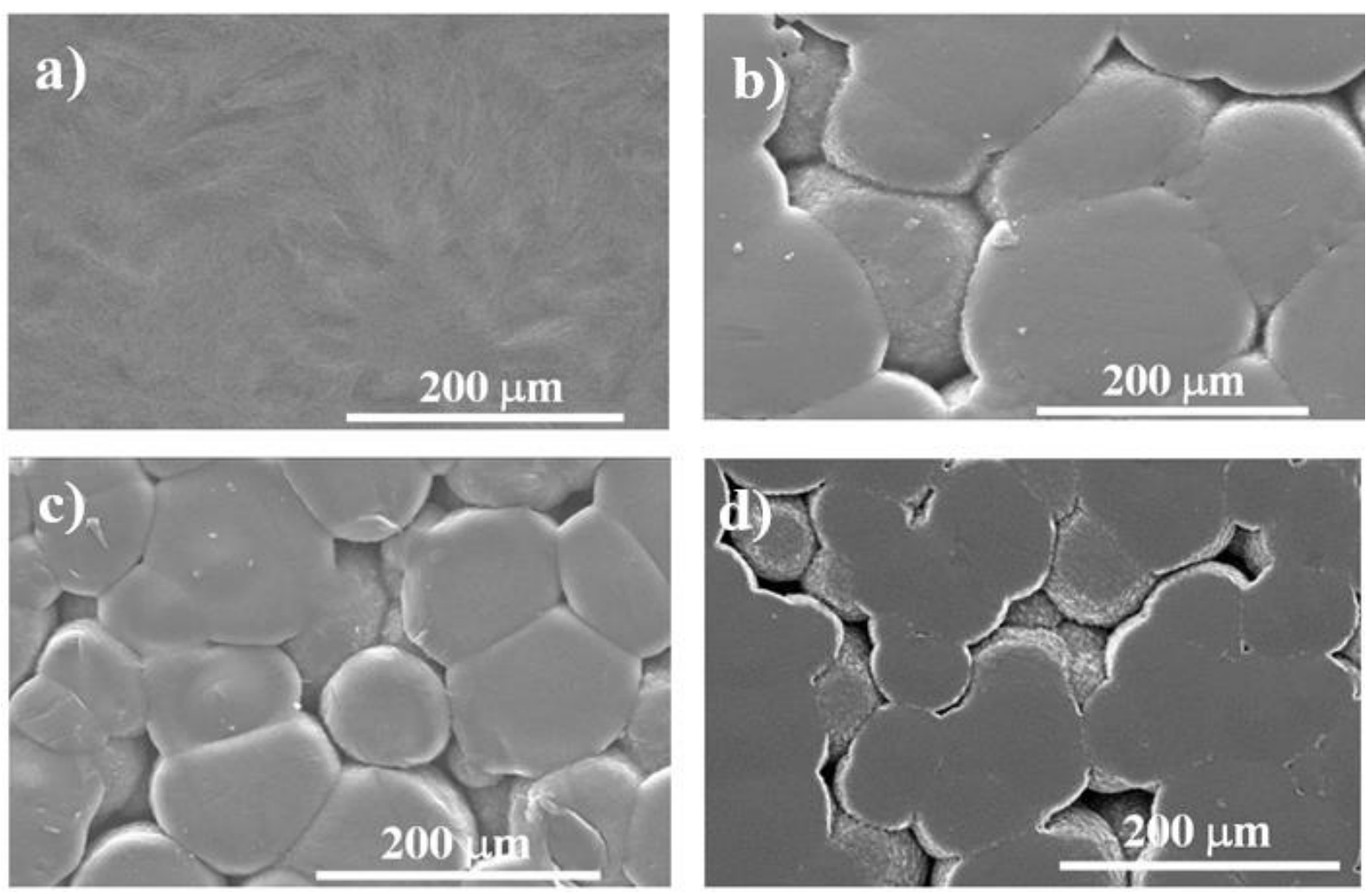

Figure 2 - SEM image of the pristine polymer (a); of IL/PVDF composites with [Cl] anion with different IL contents: $25 \%$ (b) and $40 \%$ (c) and for composites with the [ $\left.\mathrm{NTf}_{2}\right]$ anion with $40 \%$ (d) IL content.

It can be observed that the spherulitic structure characteristic of PVDF (Figure 2a) is maintained but that the spherulite size deceases with increasing $\left[\mathrm{C}_{6} \mathrm{mim}\right][\mathrm{Cl}]$ filler content (Figure $2 \mathrm{~b}$ and $\mathrm{c}$ ). Further, the borders between spherulites become more evident, leading 
to the appearance of voids. These images and the corresponding conclusions are also representative for the samples with $\left[\mathrm{C}_{6} \mathrm{mim}\right]\left[\mathrm{NTf}_{2}\right]$ as filler (Figure $2 \mathrm{~d}$ ), the results being thus independent of the anion type. The decrease in the average spherulite size and therefore the increase in their number is due to two factors: first, the ionic liquids act as nucleation agents $[33,34]$, promoting a larger number of crystallization nucleus and therefore leading to spherulites with smaller sizes; second, the strong electrostatic interactions between the IL with the local dipole moments of the polymer chains, strongly affects polymer crystallization kinetics [35].

It is also to notice that when the nuclei density is high (Figures $2 \mathrm{c}$ and $2 \mathrm{~d}$ ), the nuclei of the spherulites are too close to each other, hindering free growth and leading to spherulites with well-defined borders and even with the presence of voids [36]. The main difference between the samples with IL containing $[\mathrm{Cl}]$ or $\left[\mathrm{NTf}_{2}\right]$ as anions is that, for a given IL content, the samples with $\left[\mathrm{NTf}_{2}\right]$ show slightly smaller spherulite sizes, indicating stronger interaction with the polymer due to the larger anion size. 


\subsubsection{Electroactive phase content}

The identification and quantification of the crystalline forms of PVDF ( $\alpha$-, $\beta$ - or $\gamma$-phase) was performed by FTIR spectroscopy [27]. Figure 3 shows the FTIR-ATIR spectra for the different IL/PVDF composites.
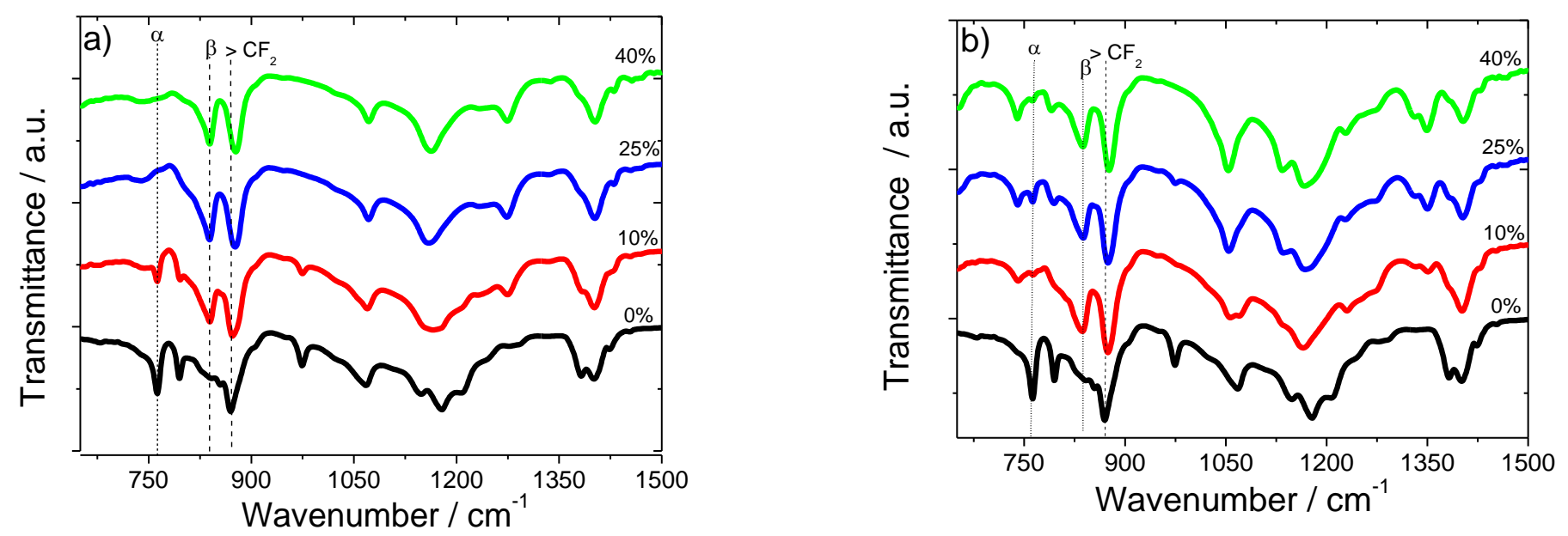

Figure 3 - FTIR-ATR spectra of pristine PVDF and IL/PVDF composites with 10, 25 and $40 \mathrm{wt} \%\left[\mathrm{C}_{6} \mathrm{mim}\right][\mathrm{Cl}]$ (a) and $\left[\mathrm{C}_{6} \mathrm{mim}\right]\left[\mathrm{NTf}_{2}\right]$ (b) content.

The pristine polymer crystallizes in the nonpolar $\alpha$-phase, as indicated by the bands at $766,795,855$ and $976 \mathrm{~cm}^{-1}$ and the absence of bands identified with the $\beta$-phase (840 and $1279 \mathrm{~cm}^{-1}$ ) [27]. Moreover, for both IL type, the characteristic bands of the $\beta$-phase increase and the ones corresponding to the $\alpha$-phase decrease with increasing of IL content, independently of the anion type. No traces of the $\gamma$-phase are observed. Thus, it is concluded that the presence of the IL induces the PVDF polar crystalline $\beta$-phase during the crystallization of the polymer. Similar results have been reported for the $\left[\mathrm{C}_{2} \mathrm{mim}\right]\left[\mathrm{NTf}_{2}\right][29,37]$ and $\left[\mathrm{C}_{4} \mathrm{mim}\right]\left[\mathrm{PF}_{6}\right][38] \mathrm{IL} / \mathrm{PVDF}$ composites.

The nucleation of the crystalline $\beta$-phase of PVDF is attributed to the electrostatic interactions between the ionic liquid and the dipoles of the PVDF chains through ion- 
dipole interactions, leading to preferred crystallization in the all-trans chain conformation of PVDF [33, 34].

The crystalline phase content of the different phases present in the IL/PVDF composites can be quantified by applying equation 4 , once the sample contains only $\alpha$ and $\beta$ phases [27]:

$$
F(\beta)=\frac{X_{\beta}}{X_{\alpha}+X_{\beta}}=\frac{A_{\beta}}{\left(K_{\beta} / K_{\alpha}\right) A_{\alpha}+A_{\beta}}
$$

where $A_{\alpha}$ and $A_{\beta}$ represent the absorbance at 766 and $840 \mathrm{~cm}^{-1}$ and $\mathrm{K}_{\alpha}$ and $\mathrm{K}_{\beta}$ are the absorption coefficients at the respective wavenumber, which values are $6.1 \times 10^{4}$ and $7.7 \times$ $10^{4} \mathrm{~cm}^{2} \mathrm{~mol}^{-1}$, respectively.

The polar $\beta$-phase content in the different samples, calculated after equation 4 , is shown in Table 1.

Table 1 - $\beta$-phase, melting temperature and degree of crystallinity of PVDF and the corresponding IL/PVDF composites.

\begin{tabular}{|c|c|c|c|}
\hline Sample & $\boldsymbol{\beta}$ phase $\pm \mathbf{5} \%$ & Melting temperature $\pm \mathbf{2}{ }^{\circ} \mathrm{C}$ & $\boldsymbol{\Delta} \boldsymbol{\chi} \pm \mathbf{4} \%$ \\
\hline PVDF & 0 & 170 & 52 \\
\hline $\mathbf{1 0 \%},[\mathrm{Cl}]$ & 67 & 169 & 39 \\
\hline $\mathbf{2 5 \%},[\mathbf{C l}]$ & 89 & 161 & 36 \\
\hline $\mathbf{4 0} \%,[\mathbf{C l}]$ & 100 & 151 & 37 \\
\hline
\end{tabular}




\begin{tabular}{|c|c|c|c|}
\hline $\mathbf{1 0 \%},\left[\mathbf{N t f}_{2}\right]$ & 93 & 171 & 55 \\
\hline $\mathbf{2 5} \%,\left[\mathbf{N t f}_{2}\right]$ & 80 & 165 & 42 \\
& & & \\
\hline $\mathbf{4 0 \%},\left[\mathbf{N t f}_{2}\right]$ & 90 & 162 & 47 \\
\hline
\end{tabular}

For $\left[\mathrm{C}_{6} \mathrm{mim}\right][\mathrm{Cl}] \mathrm{IL}$, the incorporation of $10 \%$ wt IL leads to a nucleation of the $\beta$-phase up to $67 \%$, which further increase up to $100 \%$ with an IL content of $40 \%$ wt (Table 1). On the other hand, the incorporation of $\left[\mathrm{C}_{6} \mathrm{mim}\right]\left[\mathrm{NTf}_{2}\right]$ leads to the nearly full nucleation of the polymer in the polar $\beta$-phase (above $90 \% \beta$-phase content), independently of the filler content, indicating, as already observed with respect to the morphology, a larger interaction of this anion with the polymer chains, which is related to the anion size.

Since the size of $\left[\mathrm{NTf}_{2}\right]$ anion is larger than the size of the $[\mathrm{Cl}]$ anion, it leads to larger electrostatic interactions between the negative charge of the IL anion with the positive side of the PVDF dipolar moments, promoting the crystallization of the polymer chains in the all-trans chain conformation of the $\beta$-phase for smaller amounts of IL [34].

For imidazolium ions, the miscibility and interaction between PVDF and IL is confirmed by the FTIR-ATR spectra of Figure 3 through of the $\mathrm{CF}_{2}-\mathrm{CH}_{2}$ vibration band [38]. Whereas for pristine PVDF this characteristic band is located at $875 \mathrm{~cm}^{-1}$ [39], this band gradually shifts to higher wavenumber with increasing IL content, independently of the IL type, indicating the interaction of the $\mathrm{CF}_{2}$ groups from the PVDF chains with the imidazolium ring in the IL [38]. 


\subsubsection{Degree of crystallinity and melting temperature}

Variations in the degree of crystallinity and melting temperature with IL type and content were evaluated after the DSC measurements shown in Figure 4.
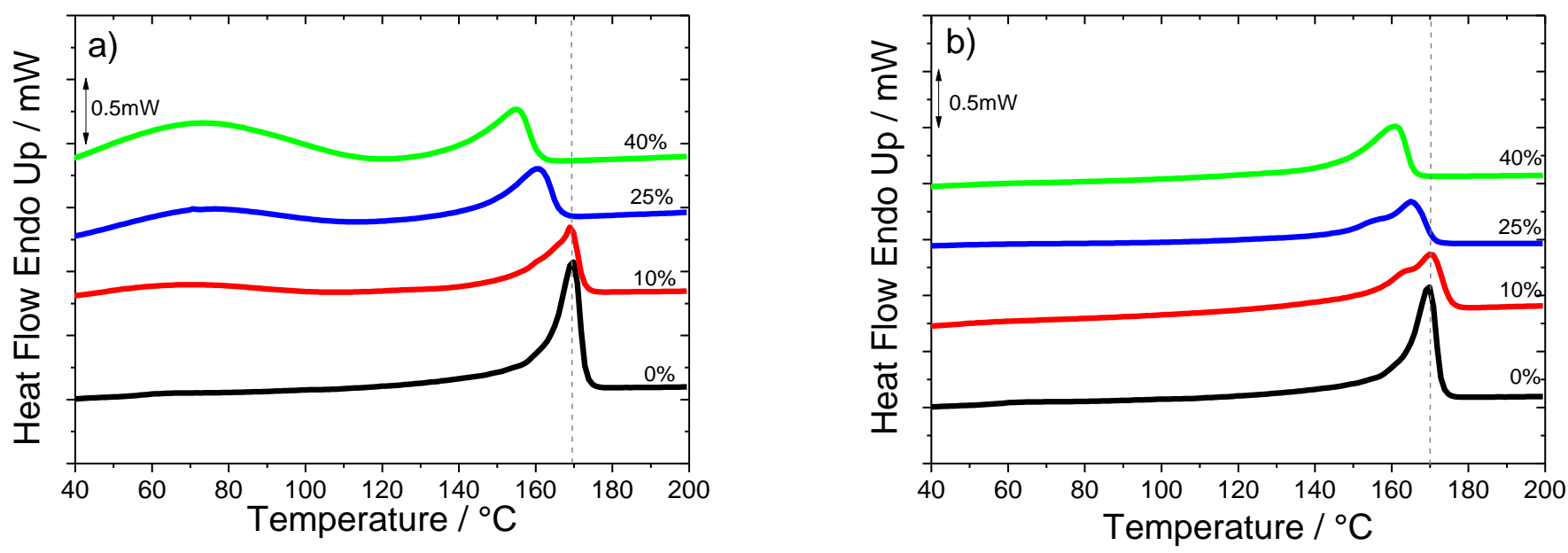

Figure 4 - DSC scans of pristine PVDF and IL/PVDF composites with 10, 25 and 40 wt $\%$ of $\left[\mathrm{C}_{6} \mathrm{mim}\right][\mathrm{Cl}]$ (a) and $\left[\mathrm{C}_{6} \mathrm{mim}\right]\left[\mathrm{NTf}_{2}\right](\mathrm{b})$.

All samples are characterized by a single endotherm peak, indicative of the melting of PVDF (Figure 4).

Independently of the IL type, it is observed a shift of the melting temperature to lower values with increasing IL content, that represent a destabilization of the crystalline phase (Table 1) due to the electrostatic interaction with the IL.

Figure $4 \mathrm{a}$ also shows an endothermic peak around $\sim 70{ }^{\circ} \mathrm{C}$ for the samples with $\left[\mathrm{C}_{6} \operatorname{mim}\right][\mathrm{Cl}]$, which increases with increasing IL content. This peak is ascribed to the presence of water in the IL/PVDF composites [37], the water content in the surface structure of $\left[\mathrm{C}_{6} \mathrm{mim}\right][\mathrm{Cl}]$ being related to the influence of the intermolecular forces between cation and anion alone [40]. For chloride anion and $\left[\mathrm{C}_{2} \mathrm{mim}\right]^{+}$cation, $2 \mathrm{H}_{2} \mathrm{O}-2 \mathrm{Cl}$ clusters are typically formed [40], as verified in this work. It is also possible that water molecules and ions aggregate in a variety of different clusters, facilitated by hydrogen bonding. The presence of water weakens the ionic interactions in ILs due to competitive 
hydrogen bonding, but in the present case the amount of water molecules is small and just affects the surface structure [40].

The degree of crystallinity of the samples (table 1) was obtained by applying equation 5 :

$$
\Delta X_{C}=\frac{\Delta H_{S}}{x \Delta H_{\alpha}+y \Delta H_{\beta}}
$$

where $\Delta H_{s}$ represents the melting enthalpy of the sample and $\Delta H_{\alpha}$ and $\Delta H_{\beta}$ are the melting enthalpies of a $100 \%$ crystalline sample in the $\alpha$ and $\beta$-phase $\left(93.07 \mathrm{Jg}^{-1}\right.$ and 103.4 $\left.\mathrm{Jg}^{-1}[27,41]\right)$, respectively. Further, $x$ and $y$ represent phase content of the $\alpha$ and $\beta$ phases present in the sample, respectively, as obtained from the FTIR experiments (Table 1).

Table 1 shows the melting temperature and degree of crystallinity of the ILs/PVDF composites, indicating that the degree of crystallinity is affected by the IL type and content present in the composite.

The presence of both IL fillers lead to a decrease of the degree of crystallinity of the polymer, being this stronger for the samples with $\left[\mathrm{C}_{6} \mathrm{mim}\right][\mathrm{Cl}]$ in comparison with the ones with $\left[\mathrm{C}_{6} \mathrm{mim}\right]\left[\mathrm{NTf}_{2}\right]$. Further, the decrease of the degree of crystallinity is almost independent on the filler content. In this way, the $\left[\mathrm{C}_{6} \mathrm{mim}\right][\mathrm{Cl}]$ filler acts as a defect into the PVDF structure, whereas the stronger electrostatic interactions of the $\left[\mathrm{C}_{6}\right.$ mim] $\left.] \mathrm{NTf}_{2}\right]$ lead to a stronger effect on the crystallization process and to a larger degree of crystallinity for a given IL concentration in comparison with $\left[\mathrm{C}_{6} \mathrm{mim}\right][\mathrm{Cl}]$. It is to notice that those results are in agreement with the FTIR and SEM results.

Thus, Table 1 shows that IL type influences the degree of crystallinity of the samples, which in turn will be reflected in the mechanical and electrical properties of the materials. 


\subsection{Mechanical properties}

For electromechanical actuator applications, the evaluation of the mechanical properties of the IL/PVDF composites is one of the key issues as it directly affects actuator performance. Representative stress-strain curves for the IL/PVDF composites with $\left[\mathrm{C}_{6} \operatorname{mim}\right][\mathrm{Cl}]$ content are shown in Figure 5, being also representative for the $\left[\mathrm{C}_{6} \operatorname{mim}\right]\left[\mathrm{NTf}_{2}\right]$ samples (not shown).

Figure 5 shows the mechanical behavior typical of the thermoplastic polymer independently of the IL content, being therefore characterized by a linear elastic regime (where the Young Modulus is determined) and the yielding stress (limiting the elastic and plastic regions) [42].
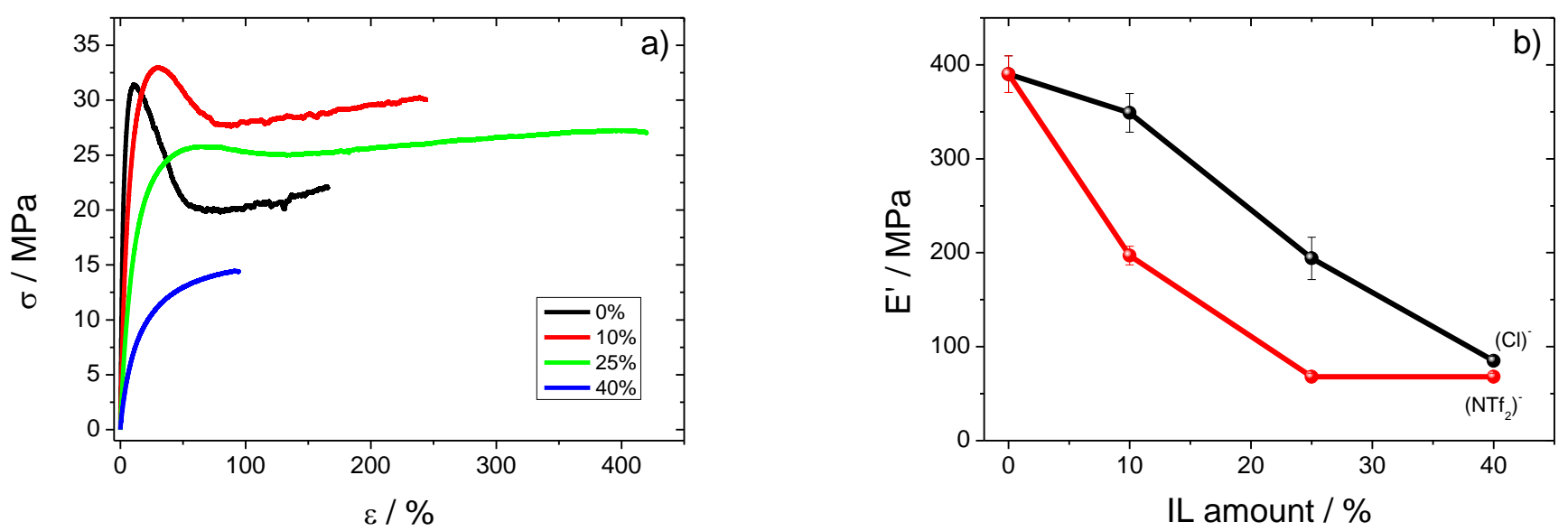

Figure 5 - Stress-strain curves for $\left[\mathrm{C}_{6} \mathrm{mim}\right][\mathrm{Cl}] / \mathrm{PVDF}$ composites (a) and elastic modulus (E') for the different samples (b).

Figure 5a shows that the IL content deeply influences the mechanical properties of the polymer, the elastic modulus and the yielding stress generically decreasing with increasing IL content. Further, the yielding strain is largely broadened with the addition of IL, indicating that both IL types act as plasticizer within the polymer matrix [29]. 
The elastic modulus (Figure 5b), obtained from a linear fit up to a deformation of $4 \%$, not only decreases with increasing IL content, but also is lower for the composites with $\left[\mathrm{NTF}_{2}\right]^{-}$anion in comparison to the ones with $[\mathrm{Cl}]^{-}$anion. Thus, as the degree of crystallinity is larger for the $\left[\mathrm{NTF}_{2}\right]^{-}$anion containing samples and the mechanical properties are determined mainly by the amorphous part of the material, in which the IL is placed, the higher relative IL content in the amorphous part of the material for that anion leads to a higher plasticizer effect and therefore to a lower elastic modulus. 


\subsection{Electrical properties}

Figure 6 a-c shows the real part of the dielectric constant and the a.c. conductivity for the pure polymer and the $\left[\mathrm{C}_{6} \mathrm{mim}\right]\left[\mathrm{NTf}_{2}\right] / \mathrm{PVDF}$ composites with different ILs contents as a function of frequency at $23^{\circ} \mathrm{C}$, the behavior being also representative for the $\left[\mathrm{C}_{6} \mathrm{mim}\right][\mathrm{Cl}] / \mathrm{PVDF}$ composites (data not shown).
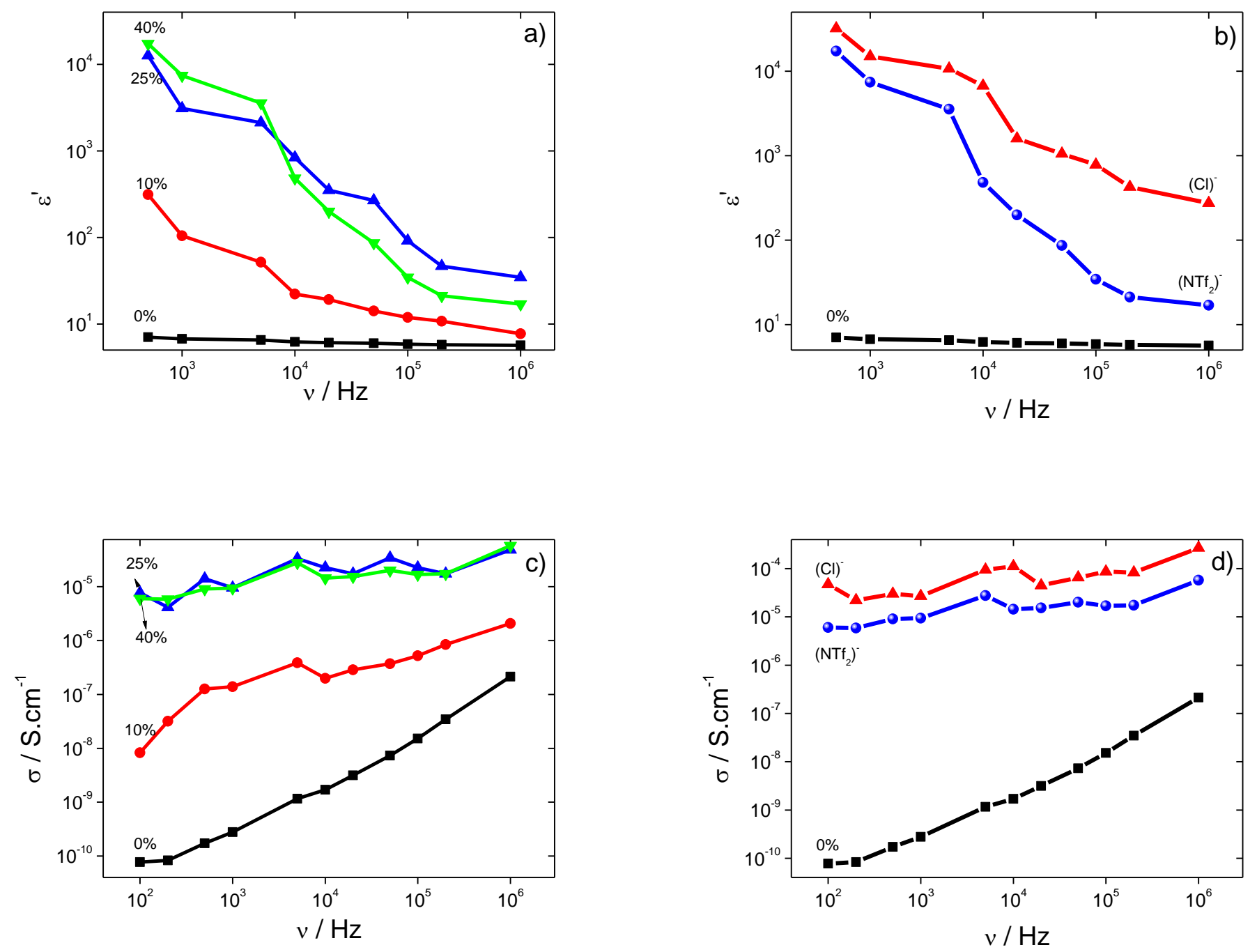

Figure 6 - Dielectric (a) and a.c. conductivity (c) for the different $\left[\mathrm{C}_{6} \mathrm{mim}\right]\left[\mathrm{NTf}_{2}\right] / \mathrm{PVDF}$ composites as a function of frequency. For $40 \%$ wt IL content and both IL types, dielectric (b) and a.c. conductivity (d) as a function of frequency.

Figure 6a-c shows that the addition of IL increases the dielectric constant and a.c. conductivity in comparison to the pristine polymer matrix [43]. This behavior is due to 
dissociation and ion transport of the ionic liquid resulting in higher carrier numbers within the polymer matrix [44]. For IL contents above $25 \%$ wt (Figure 6a and c) a trend to saturation both in the dielectric constant and a.c. conductivity is observed.

For high IL contents (40\%), Figure $6 \mathrm{~b}$ and d shows that the dielectric constant and a.c. conductivity depends on the type of anion present in the ionic liquid: as the size of the cation is the same for both IL types, it is shown that ions diffusion is strongly influenced by the size of the anion, being higher for the anion type with smaller size $([\mathrm{Cl}])$. In this sense, the mobility is further improved for the samples with lower degree of crystallinity ([ $\left.\left.\mathrm{C}_{6} \mathrm{mim}\right][\mathrm{Cl}] / \mathrm{PVDF}\right)$, allowing higher ion mobility.

\subsection{Bending actuation response}

Independently of IL type, the IL/PVDF composites with the best ionic conductivity are the samples with $40 \% \mathrm{wt}$ IL content, the bending performance being determined for these samples due to the higher number and mobility of ions. Thus, Figure 7 shows the bending response generated by the migration and accumulation of ions as a function of time for different voltages and the same frequency of $0.1 \mathrm{~Hz}$ (see also supplementary videos $\left[\mathrm{C}_{6} \mathrm{mim}\right][\mathrm{Cl}]$ and $\left.\left[\mathrm{C}_{6} \mathrm{mim}\right]\left[\mathrm{NTf}_{2}\right]\right)$. Typically, the bending response decreases with increasing frequency due to the low ion mobility in the polymer layers, the maximum frequency reported in the literature being also below $0.5 \mathrm{~Hz}$, as for higher frequency, the movement of ions is at lower speed than the voltage polarity switch [22]. 

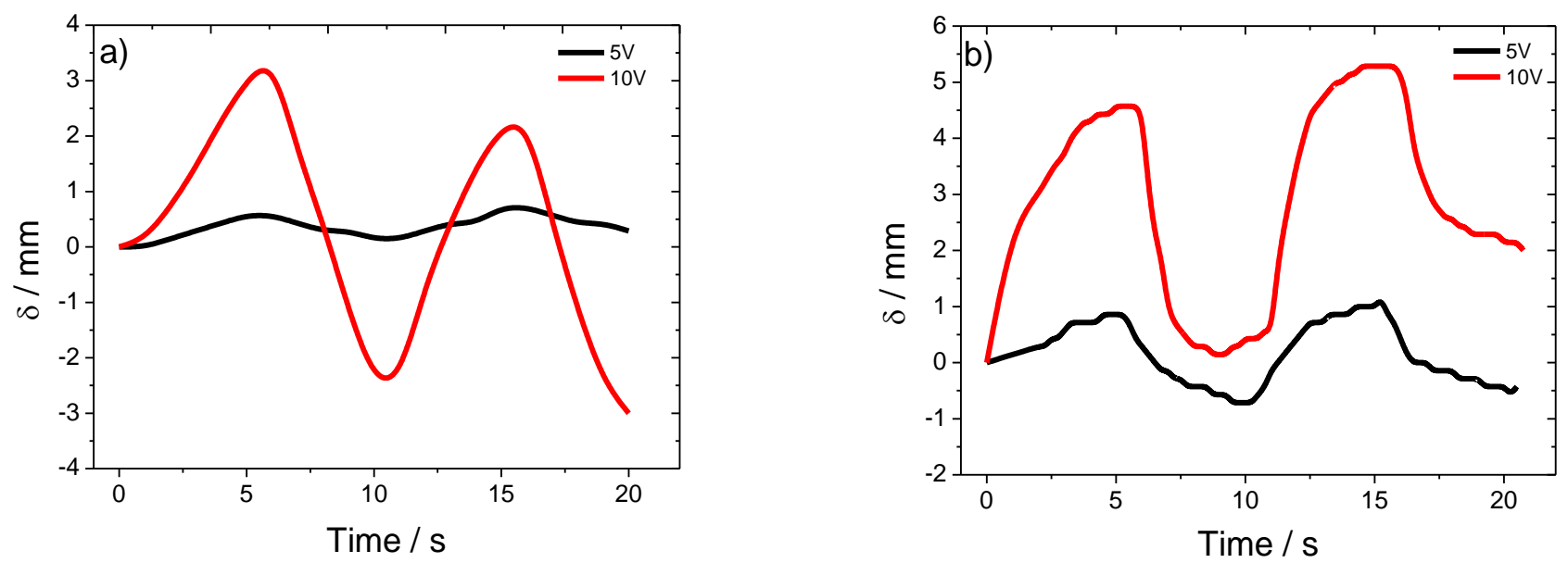

Figure 7 - Displacement of the IL/PVDF composites as a function of time under an applied voltage of 5 and 10 Volts at a frequency of $0.1 \mathrm{~Hz}$ for: a) $40 \%$ wt of $\left[\mathrm{C}_{6} \mathrm{mim}\right]\left[\mathrm{NTf}_{2}\right]$ and b) $40 \%$ wt of $\left[\mathrm{C}_{6} \mathrm{mim}\right][\mathrm{Cl}]$.

Figure 7 shows the displacement $(\delta)$ measured from the position of the actuator tip (represented in the Figure 1) as a function of time for different voltages. The displacement is determined by the diffusion of anions of cations near the electrodes (due to the ion concentration gradient) that is related to the conductivity of the PVDF/IL composites.

Independently of IL type, it is observed that the displacement increases with increasing applied voltage, correlated with the flowing current between electrodes. The bending movement under the applied voltage is due to the movement of the anions and cations present in the IL to the negative and positive electrode layers, respectively, forming an electric double layer. It is also observed that the displacement is not symmetric with respect to the initial position, due to ion irreversible movement and relaxation, i.e, the physical result of the motion and accumulation of the anion from IL [45]. This is particularly relevant for the sample with $\left[\mathrm{C}_{6} \mathrm{mim}\right][\mathrm{Cl}]$, which for the larger potential, just suffer actuation towards one direction, indicating a nonreversible separation of the ions 
within the actuator structure. This behavior is related with the fact that, due to the smaller size and larger size difference between the anions and cations, more ions can be accommodated near the electrodes, which in turn boosts the overall bending curvature. For $10 \mathrm{~V}$, the maximum displacement is $4.4 \mathrm{~mm}$ for the samples with the $[\mathrm{Cl}]$ anion and $3.4 \mathrm{~mm}$ for the $\left[\mathrm{NTf}_{2}\right]$ anion.

Thus, there are not only differences on the actuation range but also on the behavior (one direction actuation for the $\left[\mathrm{C}_{6} \mathrm{mim}\right][\mathrm{Cl}] \mathrm{IL}$ due to the lower anion size and therefore larger ionic gradient along the actuator.

Figure 8 shows a picture of the bending motion for $40 \%$ wt of $\left[\mathrm{C}_{6} \mathrm{mim}\right]\left[\mathrm{NTf}_{2}\right]$ of the 10 $\mathrm{mm} \times 2 \mathrm{~mm}$ sized actuator strip under a \pm 10 Volts square signal, showing the large bending for a positive voltage. This bending motion is representative for the samples with $\left[\mathrm{C}_{6} \operatorname{mim}\right][\mathrm{Cl}] \mathrm{IL}$.

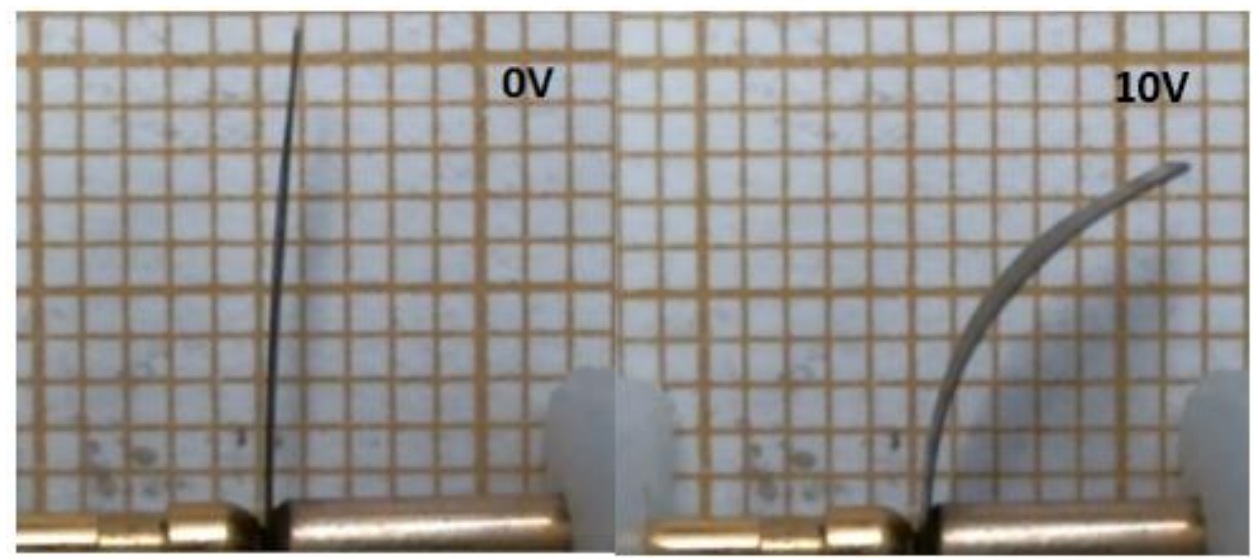

Figure 8 - Performance of the actuator under an applied voltage of 10 Volts square signal and frequency of $0.1 \mathrm{~Hz}$ for $40 \mathrm{wt} \%$ of $\left[\mathrm{C}_{6} \operatorname{mim}\right]\left[\mathrm{NTf}_{2}\right]$.

Table 2 summarizes the main parameters (displacement, bending and curvature) calculated for the IL/PVDF composite with 40\%wt IL for an applied voltage of 10 Volts 
square signal and a frequency of $0.1 \mathrm{~Hz}$. The bending and curvature parameters were determined after equation 2 and 3, respectively (see also Figure 1).

Table 2 - Displacement, bending and curvature for the IL/PVDF composites with $40 \% \mathrm{wt}$ IL content at 10 Volts square signal and $0.1 \mathrm{~Hz}$.

\begin{tabular}{|c|c|c|}
\hline \multirow{2}{*}{ Parameter } & \multicolumn{2}{|c|}{ Samples } \\
\hline & $40 \% \pm 1 \%,\left[\mathrm{NTf}_{2}\right]$ & $40 \% \pm 1 \%,[\mathrm{Cl}]$ \\
\hline 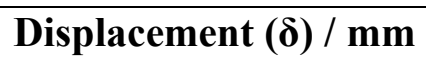 & 3.4 & 4.4 \\
\hline Bending (E) / \% & 0.5 & 0.53 \\
\hline Curvature (1/R) / mm-1 & 0.061 & 0.074 \\
\hline
\end{tabular}

The bending response depends on the thickness of the sample [5], the samples with 40 $\%$ wt IL exhibiting large s and stable over time bending response for thickness around 75 $\mu \mathrm{m}$. The large bending response represents an improvement in comparison to the data reported in the literature for $\left[\mathrm{C}_{2} \mathrm{mim}\right]\left[\mathrm{NTf}_{2}\right] / \mathrm{PVDF}$ with 5 Volts square signal and $0.5 \mathrm{~Hz}$ and $\left[\mathrm{C}_{2} \mathrm{mim}\right][\mathrm{TFSI}] / \mathrm{PVDF}-\mathrm{HFP}[28,29,46]$. 


\section{Conclusion}

IL/PVDF composites based on $\left[\mathrm{C}_{6} \mathrm{mim}\right][\mathrm{Cl}]$ and $\left[\mathrm{C}_{6} \mathrm{mim}\right]\left[\mathrm{NTf}_{2}\right]$ were prepared by solvent casting with different ionic liquid contents. Independently of the type and content of IL, the characteristic spherulitic structure of PVDF is observed, the size of the spherulites decreasing with increasing IL content and being smaller for the larger $\left[\mathrm{NTf}_{2}\right]$ anion. Thus, the IL acts as nucleation centres during polymer crystallization, leading also to an increase of the $\beta$-phase content and a decrease of the degree of crystallinity of the samples. Further, the IL/PVDF shows lower elastic modulus that the pristine PVDF matrix and decreases with increasing IL content, opposite to the dielectric constant and a.c. conductivity, which increase with increasing IL content. Considerable bending actuations are obtained in the samples, the best value of the bending response $(0.53 \%)$ being is found for the IL/PVDF composite with $40 \%$ wt of $\left[\mathrm{C}_{6} \mathrm{mim}\right][\mathrm{Cl}]$ at 10 Volts square signal.

\section{Acknowledgments}

The authors thank the FCT- Fundação para a Ciência e Tecnologia- for financial support in the framework of the Strategic Funding UID/FIS/04650/2013, projects PTDC/EEISII/5582/2014 and PTDC/CTM-ENE/5387/2014, and grants SFRH/BD/90215/2012 (J.C.D.), SFRH/BPD/112547/2015 (C.M.C.). The authors thank Solvay for kindly supplying the high quality materials. Financial support from the Basque Government Industry Department under the ELKARTEK Program is also acknowledged. The authors express their gratitude to the Ministry of the Higher Education and Scientific Research of Tunisia for a research fellowship. 


\section{References}

[1] Y. Bar-Cohen, Electroactive Polymer (EAP) Actuators as Artificial Muscles: Reality, Potential, and Challenges, Society of Photo Optical, 2004.

[2] M. Schwartz, Smart Materials, CRC Press, 2008.

[3] C. Zheng, S. Yantao, X. Ning, T. Xiaobo, Integrated sensing for ionic polymer-metal composite actuators using PVDF thin films, Smart Materials and Structures, 16 (2007) S262.

[4] T. Fukushima, K. Asaka, A. Kosaka, T. Aida, Fully Plastic Actuator through Layerby-Layer Casting with Ionic-Liquid-Based Bucky Gel, Angewandte Chemie International Edition, 44 (2005) 2410-2413.

[5] K. Mukai, K. Asaka, K. Kiyohara, T. Sugino, I. Takeuchi, T. Fukushima, T. Aida, High performance fully plastic actuator based on ionic-liquid-based bucky gel, Electrochimica Acta, 53 (2008) 5555-5562.

[6] H. Ye, J. Huang, J.J. Xu, A. Khalfan, S.G. Greenbaum, Li Ion Conducting Polymer Gel Electrolytes Based on Ionic Liquid/PVDF-HFP Blends, Journal of The Electrochemical Society, 154 (2007) A1048-A1057.

[7] S. Ferrari, E. Quartarone, P. Mustarelli, A. Magistris, M. Fagnoni, S. Protti, C. Gerbaldi, A. Spinella, Lithium ion conducting PVdF-HFP composite gel electrolytes based on $\mathrm{N}$-methoxyethyl-N-methylpyrrolidinium bis(trifluoromethanesulfonyl)-imide ionic liquid, Journal of Power Sources, 195 (2010) 559-566.

[8] F. Carpi, E. Smela, Biomedical Applications of Electroactive Polymer Actuators, Wiley, 2009.

[9] J.C. Dias, D.C. Correia, A.C. Lopes, S. Ribeiro, C. Ribeiro, V. Sencadas, G. Botelho, J.M.S.S. Esperança, J.M. Laza, J.L. Vilas, L.M. León, S. Lanceros-Méndez, Development of poly(vinylidene fluoride)/ionic liquid electrospun fibers for tissue engineering applications, Journal of Materials Science, (2016) 1-9.

[10] R. Hagiwara, Y. Ito, Room temperature ionic liquids of alkylimidazolium cations and fluoroanions, Journal of Fluorine Chemistry, 105 (2000) 221-227.

[11] H. Niedermeyer, J.P. Hallett, I.J. Villar-Garcia, P.A. Hunt, T. Welton, Mixtures of ionic liquids, Chemical Society Reviews, 41 (2012) 7780-7802.

[12] P.C. Marr, A.C. Marr, Ionic liquid gel materials: applications in green and sustainable chemistry, Green Chemistry, (2016). 
[13] Z. Cheng, Q. Zhang, Field-Activated Electroactive Polymers, MRS Bulletin, 33 (2008) 183-187.

[14] D.Y. Lee, I.-S. Park, M.-H. Lee, K.J. Kim, S. Heo, Ionic polymer-metal composite bending actuator loaded with multi-walled carbon nanotubes, Sensors and Actuators A: Physical, 133 (2007) 117-127.

[15] J. Zhou, M. Mulle, Y. Zhang, X. Xu, E.Q. Li, F. Han, S.T. Thoroddsen, G. Lubineau, High-ampacity conductive polymer microfibers as fast response wearable heaters and electromechanical actuators, Journal of Materials Chemistry C, 4 (2016) 1238-1249.

[16] W. Lu, A.G. Fadeev, B. Qi, E. Smela, B.R. Mattes, J. Ding, G.M. Spinks, J. Mazurkiewicz, D. Zhou, G.G. Wallace, D.R. MacFarlane, S.A. Forsyth, M. Forsyth, Use of Ionic Liquids for $\pi$-Conjugated Polymer Electrochemical Devices, Science, 297 (2002) 983-987.

[17] M.D. Bennett, D.J. Leo, Ionic liquids as stable solvents for ionic polymer transducers, Sensors and Actuators A: Physical, 115 (2004) 79-90.

[18] D.R. MacFarlane, N. Tachikawa, M. Forsyth, J.M. Pringle, P.C. Howlett, G.D. Elliott, J.H. Davis, M. Watanabe, P. Simon, C.A. Angell, Energy applications of ionic liquids, Energy \& Environmental Science, 7 (2014) 232-250.

[19] M.A.B.H. Susan, T. Kaneko, A. Noda, M. Watanabe, Ion Gels Prepared by in Situ Radical Polymerization of Vinyl Monomers in an Ionic Liquid and Their Characterization as Polymer Electrolytes, Journal of the American Chemical Society, 127 (2005) 49764983.

[20] W. Jin, X. Chunye, T. Minoru, K. Yasuo, A Flemion-based actuator with ionic liquid as solvent, Smart Materials and Structures, 16 (2007) S214.

[21] A.B. McEwen, H.L. Ngo, K. LeCompte, J.L. Goldman, Electrochemical Properties of Imidazolium Salt Electrolytes for Electrochemical Capacitor Applications, Journal of The Electrochemical Society, 146 (1999) 1687-1695.

[22] O. Kim, T.J. Shin, M.J. Park, Fast low-voltage electroactive actuators using nanostructured polymer electrolytes, Nat Commun, 4 (2013).

[23] C. Jo, D. Pugal, I.-K. Oh, K.J. Kim, K. Asaka, Recent advances in ionic polymermetal composite actuators and their modeling and applications, Progress in Polymer Science, 38 (2013) 1037-1066.

[24] Z. Chen, K.-Y. Kwon, X. Tan, Integrated IPMC/PVDF sensory actuator and its validation in feedback control, Sensors and Actuators A: Physical, 144 (2008) 231-241. 
[25] Y. Liu, M. Ghaffari, R. Zhao, J.-H. Lin, M. Lin, Q. Zhang, Enhanced electromechanical response of ionic polymer actuators by improving mechanical coupling between ions and polymer matrix, Macromolecules, 45 (2012) 5128-5133.

[26] K.-S. Kwon, T.N. Ng, Improving electroactive polymer actuator by tuning ionic liquid concentration, Organic Electronics, 15 (2014) 294-298.

[27] P. Martins, A.C. Lopes, S. Lanceros-Mendez, Electroactive phases of poly(vinylidene fluoride): Determination, processing and applications, Progress in Polymer Science, 39 (2014) 683-706.

[28] K. Asaka, K. Mukai, T. Sugino, K. Kiyohara, Ionic electroactive polymer actuators based on nano-carbon electrodes, Polymer International, 62 (2013) 1263-1270.

[29] J.C. Dias, A.C. Lopes, B. Magalhães, G. Botelho, M.M. Silva, J.M.S.S. Esperança, S. Lanceros-Mendez, High performance electromechanical actuators based on ionic liquid/poly(vinylidene fluoride), Polymer Testing, 48 (2015) 199-205.

[30] A.J. Costa, M.R. Soromenho, K. Shimizu, I.M. Marrucho, J.M. Esperança, J.N.C. Lopes, L.P.N. Rebelo, Density, Thermal Expansion and Viscosity of Cholinium-Derived Ionic Liquids, ChemPhysChem, 13 (2012) 1902-1909.

[31] F. Kremer, A. Schönhals, Broadband Dielectric Spectroscopy, Springer Berlin Heidelberg, 2002.

[32] M.P. Silva, V. Sencadas, G. Botelho, A.V. Machado, A.G. Rolo, J.G. Rocha, S. Lanceros-Mendez, $\alpha$ - and $\gamma$-PVDF: Crystallization kinetics, microstructural variations and thermal behaviour, Materials Chemistry and Physics, 122 (2010) 87-92.

[33] Y. Zhu, C. Li, B. Na, R. Lv, B. Chen, J. Zhu, Polar phase formation and competition in the melt crystallization of poly (vinylidene fluoride) containing an ionic liquid, Materials Chemistry and Physics, 144 (2014) 194-198.

[34] P. Martins, C.M. Costa, M. Benelmekki, G. Botelho, S. Lanceros-Mendez, On the origin of the electroactive poly(vinylidene fluoride) [small beta]-phase nucleation by ferrite nanoparticles via surface electrostatic interactions, CrystEngComm, 14 (2012) 2807-2811.

[35] V. Sencadas, P. Martins, A. Pitães, M. Benelmekki, J.L. Gómez Ribelles, S. Lanceros-Mendez, Influence of Ferrite Nanoparticle Type and Content on the Crystallization Kinetics and Electroactive Phase Nucleation of Poly(vinylidene fluoride), Langmuir, 27 (2011) 7241-7249. 
[36] L. He, J. Sun, X. Wang, C. Wang, R. Song, Y. Hao, Facile and effective promotion of $\beta$ crystalline phase in poly(vinylidene fluoride) via the incorporation of imidazolium ionic liquids, Polymer International, 62 (2013) 638-646.

[37] R. Mejri, J.C. Dias, A.C. Lopes, S. Bebes Hentati, M.M. Silva, G. Botelho, A. Mão de Ferro, J.M.S.S. Esperança, A. Maceiras, J.M. Laza, J.L. Vilas, L.M. León, S. LancerosMendez, Effect of ionic liquid anion and cation on the physico-chemical properties of poly(vinylidene fluoride)/ionic liquid blends, European Polymer Journal, 71 (2015) 304313.

[38] C. Xing, M. Zhao, L. Zhao, J. You, X. Cao, Y. Li, Ionic liquid modified poly(vinylidene fluoride): crystalline structures, miscibility, and physical properties, Polymer Chemistry, 4 (2013) 5726-5734.

[39] S. Manna, A.K. Nandi, Piezoelectric $\beta$ Polymorph in Poly(vinylidene fluoride)Functionalized Multiwalled Carbon Nanotube Nanocomposite Films, The Journal of Physical Chemistry C, 111 (2007) 14670-14680.

[40] C. Ridings, V. Lockett, G. Andersson, Significant changes of the charge distribution at the surface of an ionic liquid due to the presence of small amounts of water, Physical Chemistry Chemical Physics, 13 (2011) 21301-21307.

[41] A. Lovinger, Poly(Vinylidene Fluoride), in: D.C. Bassett (Ed.) Developments in Crystalline Polymers-1, Springer Netherlands, 1982, pp. 195-273.

[42] C.M. Costa, V. Sencadas, I. Pelicano, F. Martins, J.G. Rocha, S. Lanceros-Mendez, Microscopic origin of the high-strain mechanical response of poled and non-poled poly(vinylidene fluoride) in the $\beta$-phase, Journal of Non-Crystalline Solids, 354 (2008) 3871-3876.

[43] V. Sencadas, S. Lanceros-Méndez, R. Sabater i Serra, A. Andrio Balado, J.L. Gómez Ribelles, Relaxation dynamics of poly(vinylidene fluoride) studied by dynamical mechanical measurements and dielectric spectroscopy, Eur. Phys. J. E, 35 (2012) 41.

[44] R. Leones, C.M. Costa, A.V. Machado, J.M.S.S. Esperança, M.M. Silva, S. Lanceros-Méndez, Development of solid polymer electrolytes based on poly(vinylidene fluoride-trifluoroethylene) and the [N1 $1112(\mathrm{OH})][\mathrm{NTf} 2]$ ionic liquid for energy storage applications, Solid State Ionics, 253 (2013) 143-150.

[45] K. Kruusamäe, A. Punning, A. Aabloo, K. Asaka, Self-Sensing Ionic Polymer Actuators: A Review, Actuators, 4 (2015) 17.

[46] N. Terasawa, N. Ono, Y. Hayakawa, K. Mukai, T. Koga, N. Higashi, K. Asaka, Effect of hexafluoropropylene on the performance of poly(vinylidene fluoride) polymer 
actuators based on single-walled carbon nanotube-ionic liquid gel, Sensors and Actuators B: Chemical, 160 (2011) 161-167. 